\title{
The Mesoscale Wind Field in an Occlusion
}

\author{
CARI W. KReitzberG ${ }^{1}$ \\ Air Force Cambridge Research Laboratories, Bedford, Mass. \\ (Manuscript received 13 June 1967, in revised form 2 October 1967)
}

\begin{abstract}
Data from a 10-site mesoscale rawinsonde network are used to document a number of features in the wind field in a mature cyclone of moderate intensity. The general nature of, and some particular phenomena in, the mesoscale wind field are discussed. Fields of divergence and vertical velocity are presented and the ageostrophic nature of the wind shear is demonstrated.

Specific features examined include mid-tropospheric oscillations in wind direction, a low-level jet stream, the coincidence of the tropopause with an ageostrophic level of maximum wind, and the jet-front shear zone.

In view of these results from AFCRL's project Stormy Spring, some of the capabilities and limitations of mesoscale rawinsonde data are discussed.
\end{abstract}

\section{The project and data}

The atmospheric structures to be discussed were observed during Project Stormy Spring, a pilot study of mesoscale features in extratropical cyclones. The observational phase of this project was conducted in March and April 1965 by the Meteorology Laboratory of the Air Force Cambridge Research Laboratories. Five storms were observed using a mesoscale network of special rawinsonde sites and automatic recording surface sites, instrumented U-2 and C-130 aircraft, special weather radars, and special observations by Weather Bureau, Coast Guard and Navy installations.

Although the primary objective of the project was the investigation of cloud features, a number of interesting wind variations were well documented by the special upper air network. This paper describes the nature of the wind variations, especially strong shear zones, in the first storm that was analyzed and indicates some of the capabilities and limitations of a mesoscale rawinsonde network.

The upper air network included 10 sites at about 60 $\mathrm{n}$ mi spacing, as shown in Fig. 1. The Weather Bureau sites at the four corners of the network (Albany, Portland, Nantucket and Kennedy Airport) took soundings at 3-hr intervals; the six Air Force sites made serial ascents at 90-min intervals. All of the soundings were converted (in great detail) to punched cards and processed as documented by Kreitzberg and Brockman (1966). The upper air data for all five storms are available to interested investigators through the National Weather Records Center.

The accuracy of GMD-1 winds, as processed for Project Stormy Spring, is consistent with random azi-

\footnotetext{
${ }^{1}$ Present affiliation: Department of Meteorology, The Pennsylvania State University, University Park.
}

muth and elevation angle errors of $0.05^{\circ}$ as listed by Dvoskin and Sissenwine (1958). This conclusion is based on a study of the departure of individual winds in the $12-16 \mathrm{~km}$ region from the mean of 36 soundings in one sample and 39 in another. Such observational errors yield errors in 2-min mean winds of less than $1 \mathrm{~m} \mathrm{sec}^{-1}$ (or $2^{\circ}$ in wind direction) for values of elevation angle and wind speed encountered throughout most of the storm to be discussed. In view of large errors in GMD-1 tracking at low elevation angles due to bogus signals, it

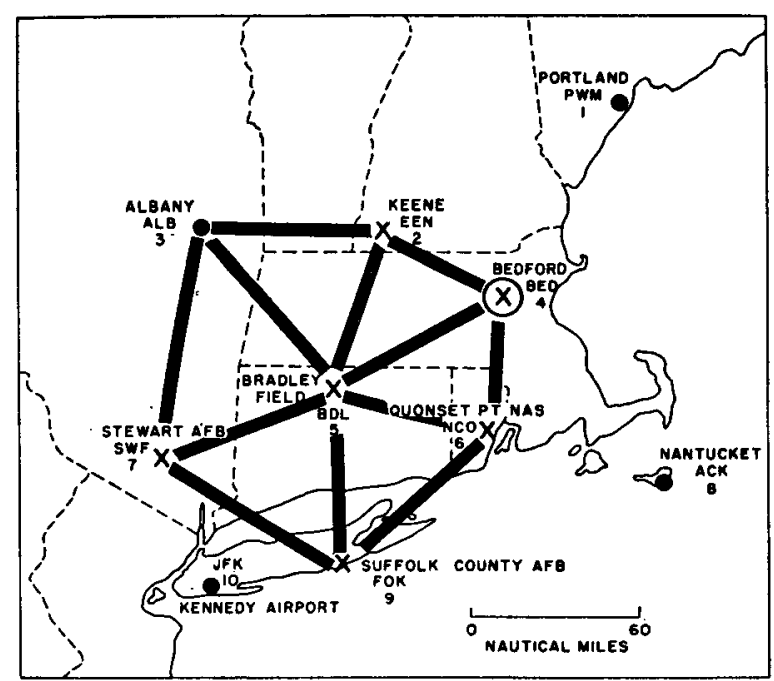

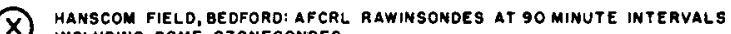
INCLUOING SOME OZONESONOES.

$X$ air weather service: mobile rawinsondes atgominute intervals.

- weather bureau rawinsondes at 3 hour intervals.

FIG. 1. Rawinsonde network for Project Stormy Spring. 
should be mentioned that the detailed winds discussed herein were all obtained at elevation angles $>10^{\circ}$.

\section{An overall view of the storm}

The mesoscale features to be discussed were embedded within a moderately intense storm which originated as a pseudo-occlusion to the lee of the Rockies
(Palmén, 1951). The surface low deepened as it moved across the central United States, over the Great Lakes, and out the St. Lawrence Seaway. The occluded front swept across New England with a trough and a tongue of cold air aloft.

Some of the principal features within the storm are summarized in Fig. 2 on a time section for Bradley
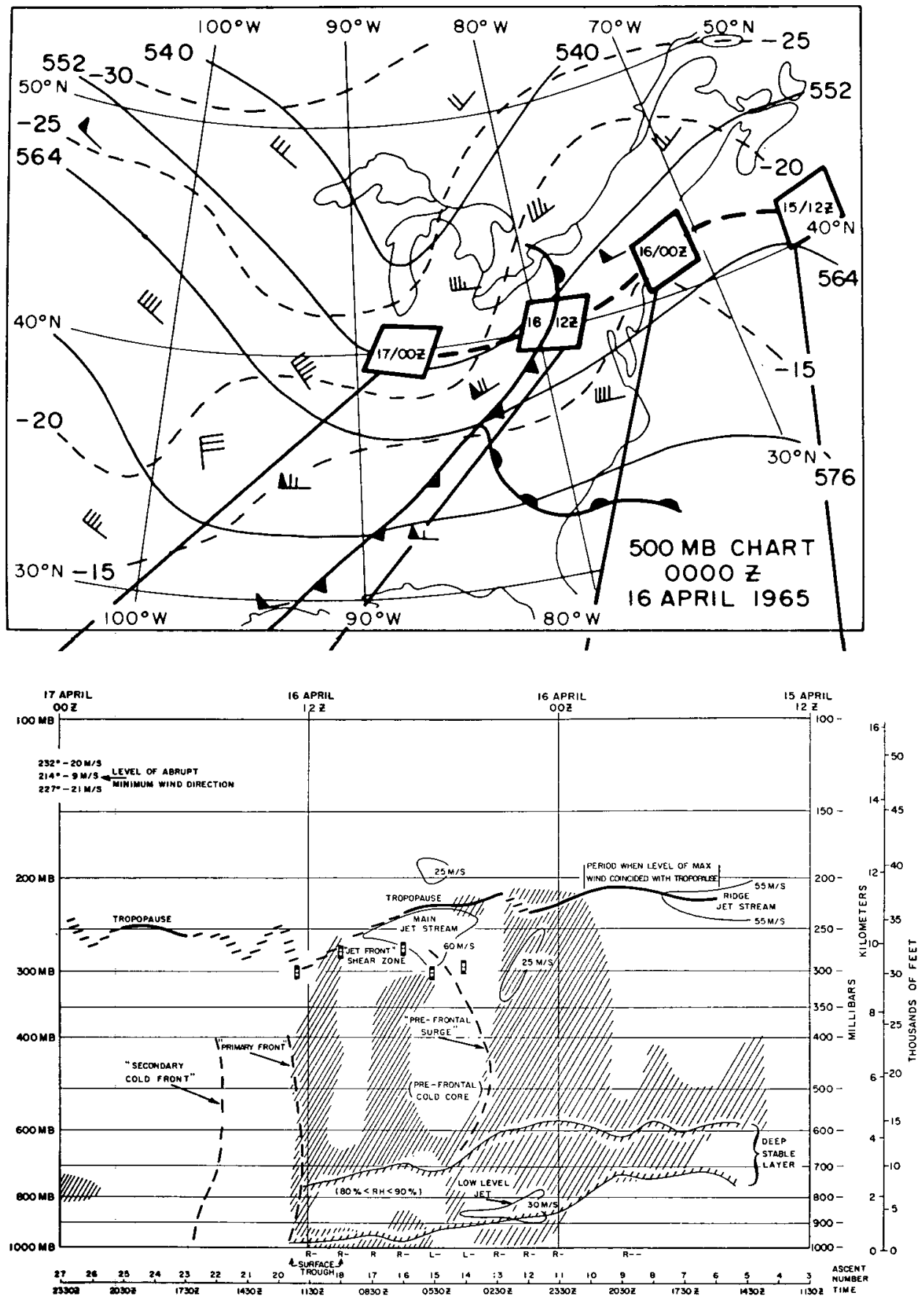

FIG. 2. Position of mesoscale features at Bradley Field, Conn. (shown on the time section, lower chart) relative to the large scale pattern at $500 \mathrm{mb}$ (upper chart). Heavy lines lead from the four synoptic times on the time section to the outlines of the Stormy Spring network located relative to the $500-\mathrm{mb}$ pattern. 
Field, Conn. The position of these features with respect to the cyclonic scale pattern is shown by reference to the $500-\mathrm{mb}$ chart for 0000 GMT 16 April. To the extent that one can consider the storm as an unchanging entity moving over the network, the time section can be visualized as a space cross section through the storm from the $500-\mathrm{mb}$ ridge to the trough as indicated. The relative and actual positions of the network coincide only at 0000 GMT 16 April.

The hatched portion of the time section in Fig. 2 indicates regions with relative humidity with respect to ice in excess of $90 \%$. The tropopause is indicated as having poor spacial and temporal continuity, particularly after passage of the main jet stream. A deep stable layer suggestive of the warm frontal zone is shown along with a prefrontal surge of cold dry air and two cyclonic scale fronts. Frontal structures on the mesoscale will be indicated on later time sections.

Wind features appearing in Fig. 2 and discussed in detail in this paper are the level of maximum wind coincident with the tropopause at 2030 GMT 15 April, the low-level jet at 0230 GMT 16 April, and the jetfront shear zone beneath the main jet at 0830 GMT 16 April.

The general nature of the wind pattern can be seen in Fig. 3 from the $50-\mathrm{mb}$ averaged winds at Bradley Field. The strong winds are grouped about the low-level jet (ascent 13), the ridge jet (ascent 5), the main jet (ascent 15), and the extensive region of strong wind between 500 and $300 \mathrm{mb}$ beginning with ascent 14 .
There is strong vertical shear beneath the three jets and general veering of wind with height in the deep stable layer and backing with height before and after passage of the primary front. The wind directions and speeds $\left(\mathrm{m} \mathrm{sec}^{-1}\right)$ at the base and top of the jet-front shear zones have been plotted.

The mesoscale frontal features are shown on this and later time sections to permit comparison with the wind features, even though detailed discussion of the thermal features is beyond the scope of this paper. These thermal features have continuity throughout the network and are, briefly:

1. A deep stable layer (corresponding roughly to a cyclonic scale warm frontal zone);

2. Two warm tongues (minor thermal features with warming ahead and cooling behind which feed into the deep stable layer);

3. A "pre-frontal surge" of cold dry air (a large mesoscale feature prominent in fields of temperature, moisture, and vertical motion);

4. The "occluded front" (the downward extension of the top of the deep stable layer which marked the end of sustained warm advection in the lower troposphere and the onset of cold advection);

5. The "primary front" (warm edge of the major hyperbaroclinic zone in the mid-troposphere, coinciding closely with the onset of strong cold advection); and

6. "Secondary cold fronts" (leading edge of periods of intense cooling usually preceded by some warming).

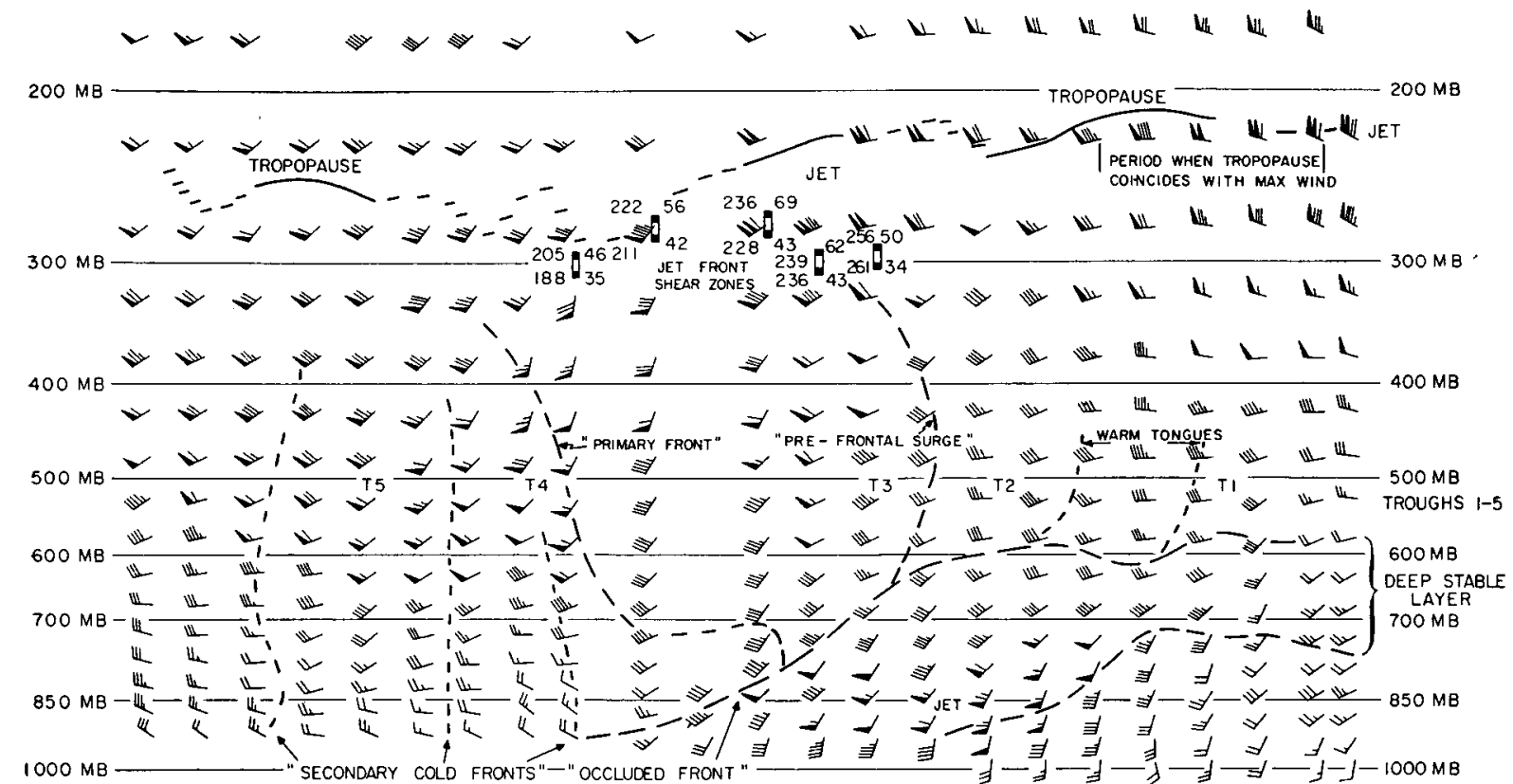

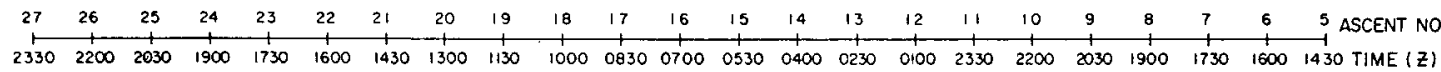

$$
\begin{aligned}
& 16 \text { APRIL } 1965 \\
& 15 \text { APRIL } 1965
\end{aligned}
$$

FIG. 3. Wind-time section for Bradley Field, Conn., with mean winds for 50 -mb layers plotted using the normal convention of a full barb equal to $5 \mathrm{~m} \mathrm{sec}^{-1}(10 \mathrm{kt})$. 
These thermal features make up the leafed structure of frontal systems which is found on the mesoscale (Kreitzberg, 1964). A cyclonic-scale frontal analysis would connect the primary front and the first of the secondary cold fronts (at ascents 19 and 20) to obtain a single steep front, occluded in the lower levels. This location coincides well with termination of the main cloud and precipitation system (Fig. 2).

The most southerly flow at $500 \mathrm{mb}$ coincides with the primary front just ahead of a streamline trough labeled T4 in Fig. 3. There are actually five mesoscale stream- line troughs labeled $\mathrm{T} 1$ through $\mathrm{T} 5$ along the $500-\mathrm{mb}$ line. To facilitate visualizing the exact wind direction changes, Fig. 4 contains both the direction change between pressure layers for each ascent and the direction change between ascents for each layer. To give some pattern to the highly variable fields, the main regions of increasing wind direction (veering) with height and with time have been cross-hatched.

The main regions of veering with time are identified with the streamline troughs T1 through T5. Detailed analysis of spacial continuity reveals that only $\mathrm{T} 4$ has a
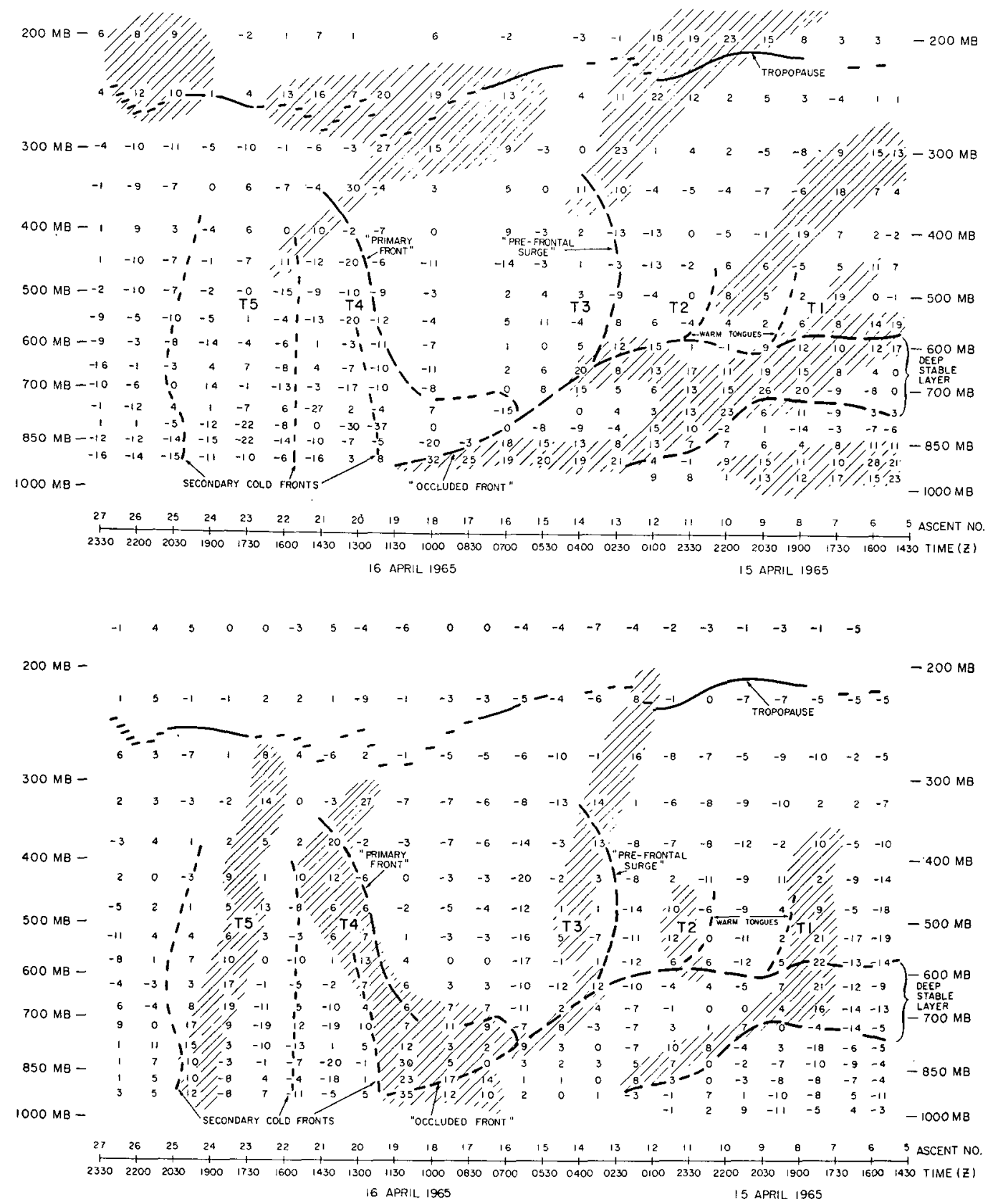

FIG. 4. Wind direction changes with height $\left[\mathrm{deg}(50 \mathrm{mb})^{-1}\right.$, upper $]$ and time $\left[\mathrm{deg} \mathrm{hr} \mathrm{h}^{-1}\right.$, lower $]$ for the winds plotted in Fig. 3. Hatched areas indicate the main regions of increasing direction (veering) with height and time. 
direct relationship to a thermal feature, namely, the "primary" front. The meso-troughs propagate at nearly the speed of the fluid so that trajectories ahead of the troughs will have origins much further south than trajectories behind the troughs. Thus, these troughs could have caused the mesoscale thermal features either directly by horizontal advection or indirectly by creating a static stability pattern leading to bands of convection and thereby a banded thermal pattern. In any case, the temperature and streamline pattern were not (or were no longer) well correlated when observed in the Stormy Spring network.

The pattern of direction changes with height above $600 \mathrm{mb}$ contains bands of veering which appear first at higher levels and descend with time. Notice that two such bands merge with the deep stable layer near the two warm tongues at soundings 8 and 10 to 11 . It is clear that any warm frontal surface located exactly at the top of a layer of strong veering wind with height would have poor mesoscale continuity.

There are numerous smaller mesoscale oscillations of direction with both height and time which have substantial amplitude but no obvious physical explanation. Some vertical changes coincide with stable laminae, but detailed analysis has shown that in the majority of cases such relations have poor continuity in space and time.

\section{Mid-tropospheric wind direction oscillations}

One of the more remarkable wind features within this storm is the series of mid-tropospheric oscillations of wind direction. These waves are seen in Fig. 4 (time changes) to be oriented vertically so that they show up clearly even when winds are averaged from 600 to
$400 \mathrm{mb}$ (about a 3-km layer). Fig. 5 shows time traces of such wind directions from the six sites taking 90-min observations. These curves have been shifted up and down to prevent overlap and have been shifted in time to account for roughly a $20 \mathrm{~m} \mathrm{sec}^{-1}$ propagation speed from west to east. The scales apply to the Bradley Field (BDL) data, but they can be shifted to fit the other curves by reference to the "十" marks which locate ascent 5 and $270^{\circ}$ for each curve.

The streamline troughs appear in Fig. 5 as points of relatively rapid increase of wind direction with time and are labeled $\mathrm{T} 1$ through $\mathrm{T} 5$. The first oscillation shows up very well at all sites and has an amplitude of $\pm 10^{\circ}$. The second trough has a SW-NE orientation and passes the northern sites (e.g., EEN) substantially ahead of the southern sites. The third feature passes through the northern half of the network only and is followed by a $20^{\circ}$ backing of the mean wind between 90 -min observations. Troughs 4 and 5 in the latter part of the storm have substantially smaller magnitudes blending into the larger scale trough. The detailed pattern of wind direction change with time (Fig. 4) shows that T4 would be more prominent with less vertical averaging.

Notice that if the observation interval had been $3 \mathrm{hr}$, these five high-frequency features would not have been properly resolved. For example, the time traces taking even numbered ascents in Fig. 5 would be substantially different from those inferred from only the odd numbered ascents; the traces from 3 -hr ascents would depend largely on the phase of observation timing. Of course, soundings at 45- rather than 90-min intervals would better resolve these features and possibly detect still higher frequency changes. The site-to-site consistency of the curves in Fig. 5 suggests, however, that

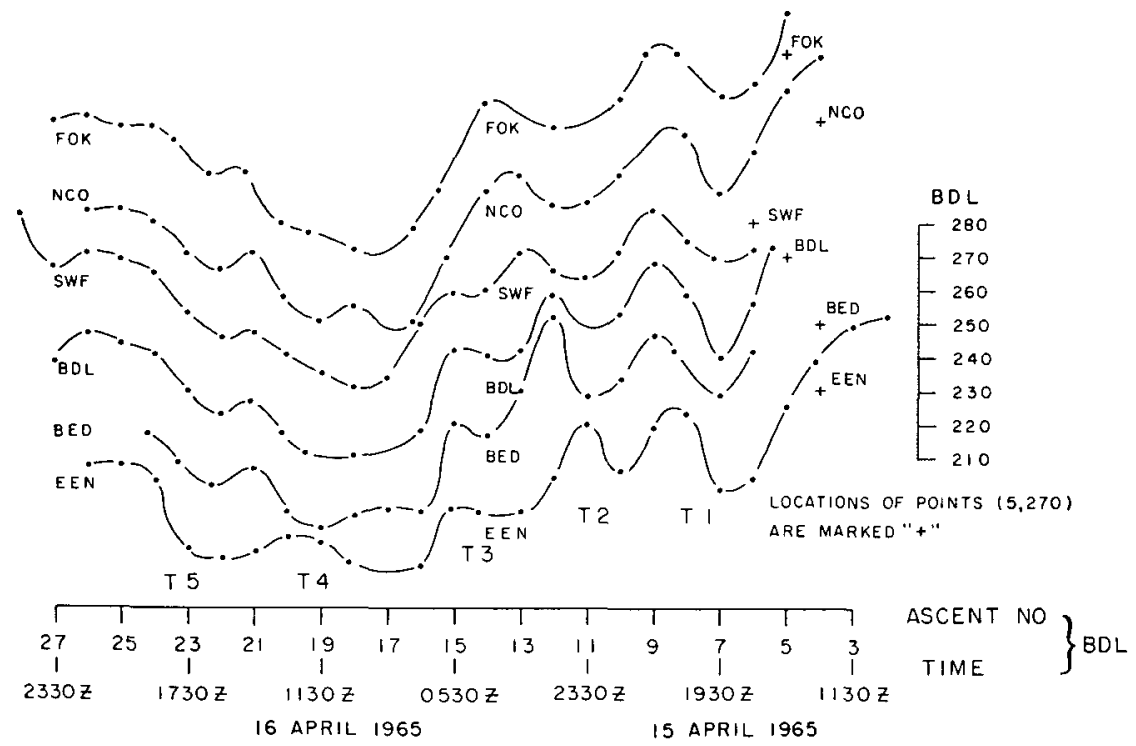

FIG. 5. Wind direction time traces for the mean direction in the $600-400 \mathrm{mb}$ layer. Scales apply only to BDL but they can be shifted for other curves by aligning $270^{\circ}$ and ascent 5 with the "+" marks. Meso-troughs are labeled T1 to T5. 


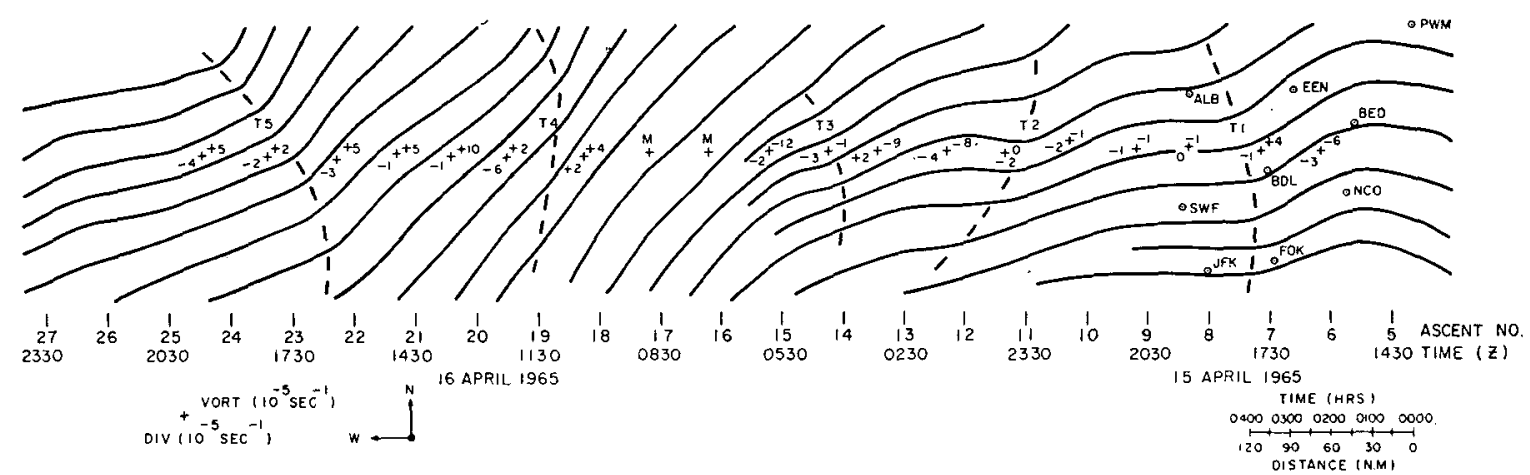

FIG. 6. Plane-time section with the $550-500 \mathrm{mb}$ layer streamlines. The orientations of the meso-troughs are shown by the dashed heavy lines.

most of the variability in these layer-mean values is resolved by the Stormy Spring observations.

The spacial structure of the mid-tropospheric streamlines is depicted with reasonable success in Fig. 6. This "plane-time section" shows the streamlines for the $550-500 \mathrm{mb}$ averaged winds. The spacial distribution of sites used in preparing this analysis is shown on the right end of the diagram and the ascent numbers and the time scale apply to BDL. The time series of data from each site was plotted by converting time to space at the rate of $1 \mathrm{hr}$ equals $30 \mathrm{n} \mathrm{mi}$ to the west. It was found that this conversion worked well at this level so that the analysis at any time does reflect the spacial field at that time. Thus, this plane-time section is like a time sequence of synoptic plane sections placed side by side with good continuity at the interfaces.

The streamline patterns with the five meso-troughs show the orientation of the troughs and their small amplitude relative to cyclonic scale troughs with long wavelengths.

The time series of relative vorticity and divergence values plotted across Fig. 6 were obtained kinematically over the area encompassed by BDL, NCO, BED and EEN (see site locations on the right). The vorticities reach maximum values in troughs 1,2 and 3 . Troughs 4 and 5 were poorly phased at observation times with respect to this one area, but the vorticity maxima observed over the area BDL, NCO, FOK, SWF were +10 and $+8\left(10^{-5} \mathrm{sec}^{-1}\right)$ for troughs 4 and 5 , respectively.

The value of the Coriolis parameter is $\sim 10 \times 10^{-5}$ $\sec ^{-1}$ at this latitude so negative absolute vorticity is shown in the meso-ridge behind trough 3 due primarily to curvature. Negative absolute vorticity on the $110-\mathrm{km}$ scale is well substantiated by horizontal and vertical continuity and is found in the middle troposphere on both sides of trough 3 , in the upper troposphere in the ridge and on the anticyclonic side of the main jet. Thus, trough 3 , and possibly troughs 1 and 2 , may have been generated from inertial instability.

There does not appear to be any systematic relation between the troughs and the divergences. Considering these calculations plus the lack of vertical wind shear with troughs 1, 2 and 3 (Fig. 3), one would expect these three waves to behave as nondivergent, barotropic inertial waves in a fluid with an oscillatory variation of vorticity along the mean flow. Estimates from the data indicate that these troughs propagate at speeds within a few meters per second of the wind component normal to them.

Detailed comparison of these wind oscillations, the leafed thermal structure, and precipitation systems located by radar and hourly precipitation patterns (report under preparation) indicate that the precipitation patterns are associated with the thermal patterns and not with these wind oscillations. This situation was not encountered by Omoto (1965) or Ferguson (1967).

\section{Temperature gradient vs. wind shear}

The capability of objectively computing meaningful subcyclonic scale gradients is demonstrated in Figs. 7 and 8 . The data were computed using serial ascents from the six sites forming a hexagonal array as indicated in Fig. 1, namely ALB, SWF, FOK, NCO, BED and EEN. To obtain data averaged in the vertical and with time commensurate with the $220-\mathrm{km}$ "diameter" of the array, data were first averaged over 100-mb deep layers and then fit in time with a least-square polynomial of eleventh degree over a period of about $36 \mathrm{hr}$. This technique compensates for off time releases and missing data while yielding about 3 -hr averaged values. These polynomials from the six sites were then evaluated at every 90-min observation time and fit in space with leastsquare error planes. The value or "height" of each plane was evaluated at Bradley Field, near the center of the hexagon, along with $x$ and $y$ slopes or derivatives. The calculations yielded such quantities as temperature and east and north wind components, $T_{0}, U_{0}, V_{0}$, and their derivatives, $T_{x}, T_{y}, U_{x}, U_{y}, V_{x}, V_{y}$, for each $100-\mathrm{mb}$ layer centered at $900,800, \ldots, 200 \mathrm{mb}$.

The upper portion of Fig. 7 shows the temperature gradients plotted with the arrows pointing toward warm air (considering the top of the figure to be north) with the length proportional to the magnitude of the gradient. The pattern is well organized with warm air 
to the west in the warm frontal stable zone turning toward the south and then the southeast as the warm tongue (occluded front) passes Bradley Field. The warm sector (600-300 mb before ascent 14 in Fig. 7, upper) is essentially barotropic, and the mid-troposphere baroclinity increases to a maximum about ascent 24 . Notice also the reversal of the temperature gradient below the tropopause after passage of the primary front.

In contrast, the lower half of Fig. 7 shows the temperature gradients implied by applying the thermal wind relation to Bradley Field wind shears over $100-\mathrm{mb}$ deep layers. The gross pattern is similar to that in the
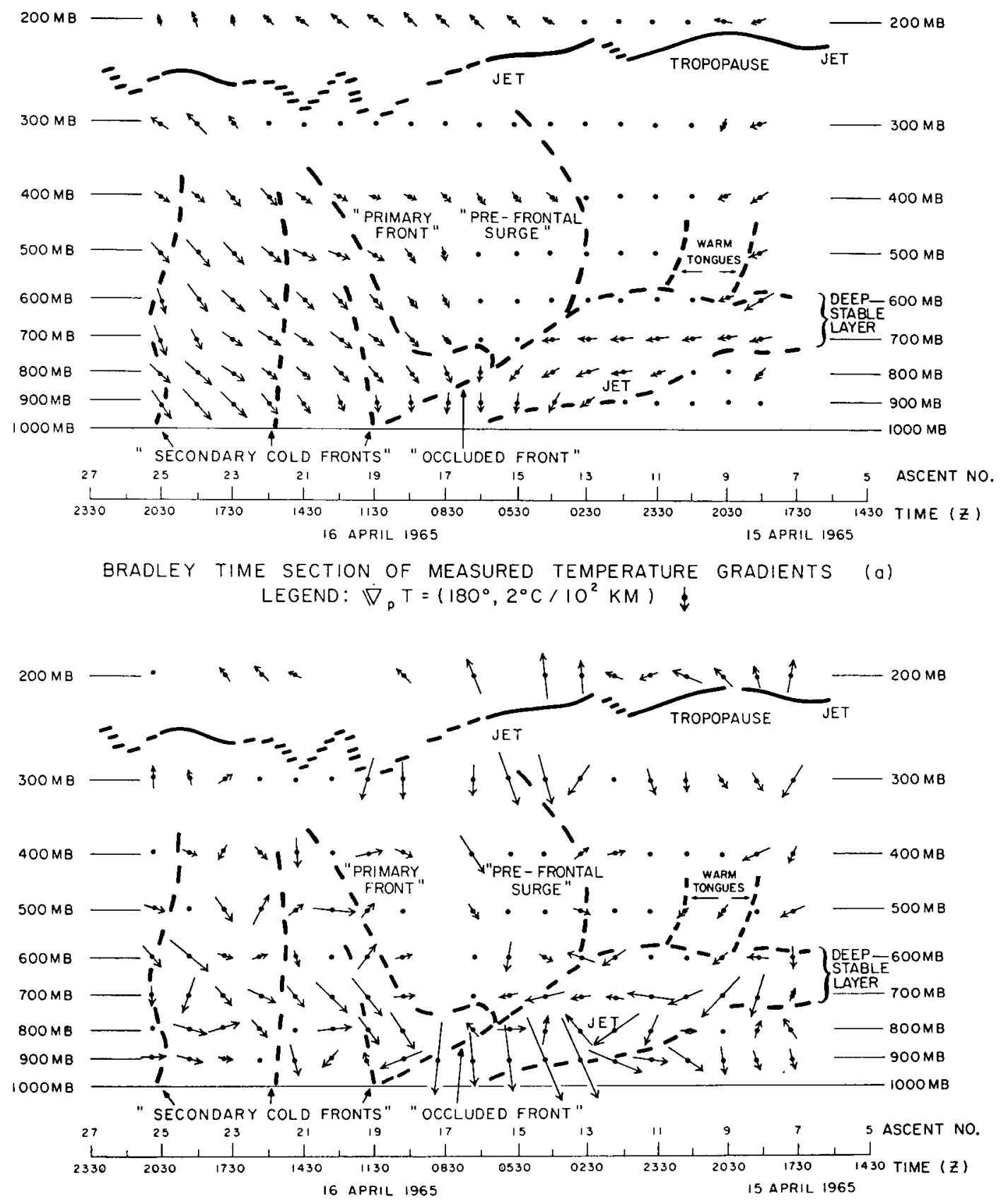

BRADLEY TIME SECTION OF TEMPERATURE GRADIENTS IMPLIED BY WIND SHEAR (b)

$$
\text { LEGEND: } \nabla_{p} T=\left(180^{\circ}, 2^{\circ} \mathrm{C} / 10^{2} \mathrm{KM}\right) \downarrow
$$

FIG. 7. Measured temperature gradients (upper) and gradients implied by the wind shear (lower). Vectors are plotted to the scale noted taking north to be at the top of the diagram. Thermal features are located with heavy lines as in Fig. 3. 


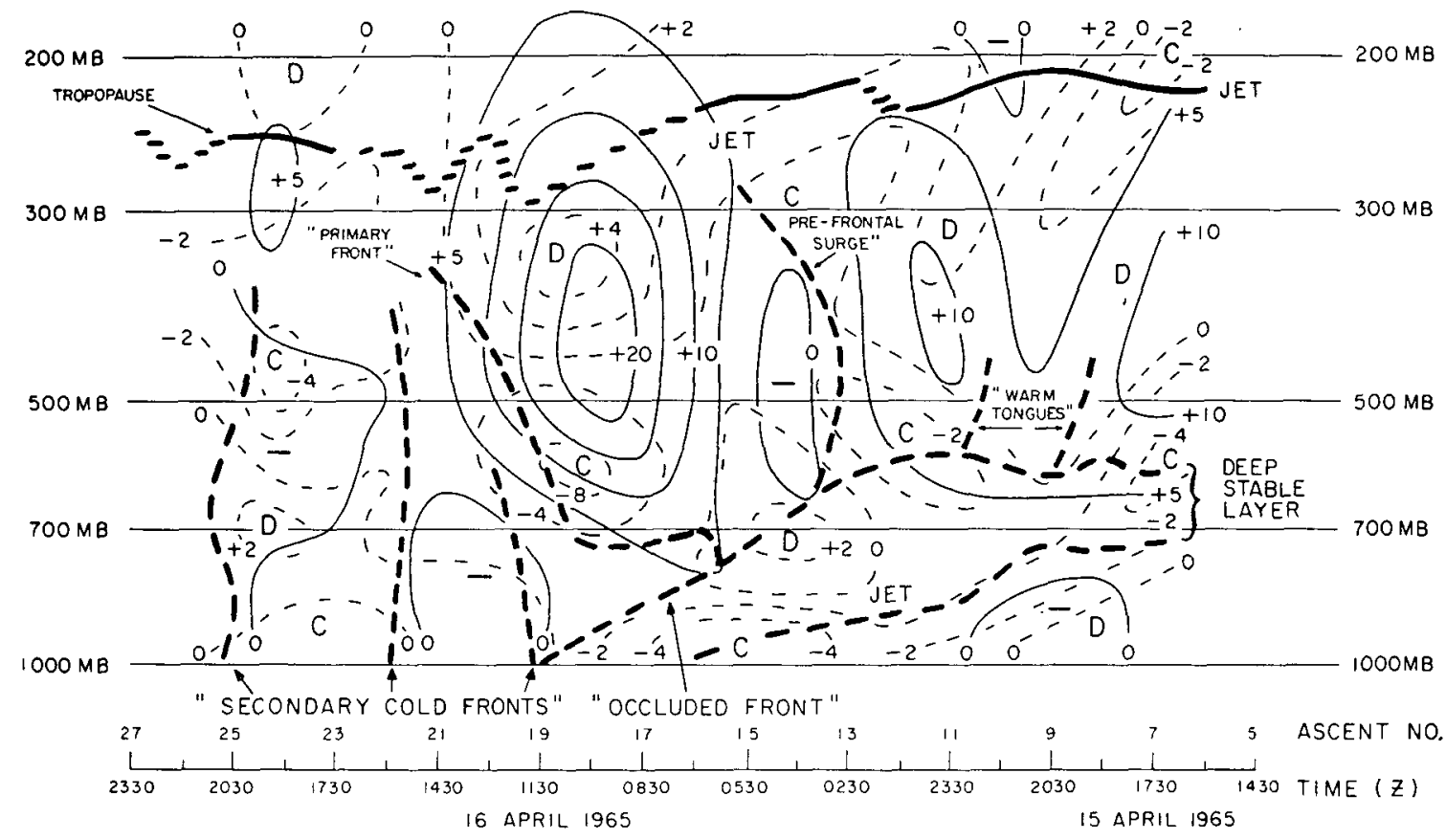

FIG. 8. Vertical velocity and divergence time section. Solid lines are vertical velocity in $\mathrm{cm} \mathrm{sec}^{-1}$ and dashed lines are divergence in $10^{-5} \mathrm{sec}^{-1}$. Centers of divergence and convergence are labeled $\mathrm{D}$ and $\mathrm{C}$ and the thermal features are located as in Fig. 3.

upper "observed" diagram, but considerable "noise" is imposed by either 1) ageostrophic vertical shears invalidating this use of the thermal wind relation, or 2) the individual hodographs reflecting a much smaller scale thermal field than that reflected in the hexagonscale temperature gradient analysis. While both factors may contribute to the contrasting patterns, the ageostrophic factor is most probably the greater. In any case, the shear from a particular hodograph cannot be considered a very useful indicator of $220 \mathrm{~km}$ scale temperature gradients.

\section{Vertical velocity and divergence}

The hexagon data were also used for the analyses in Fig. 8. The divergence is simply $\left(U_{x}+V_{y}\right)$, and the kinematic vertical motion is the vertical integral of these divergences assuming $\omega \equiv D p / D t=0$ at $950 \mathrm{mb}$. To minimize the effect of errors accumulating to give fictitious fields of vertical motion at higher levels, the $\omega$-values were arbitrarily reduced by a fraction of the $200-\mathrm{mb} \omega$ values. The fractions used were 0.8 at $200 \mathrm{mb}$, 0.6 at $300 \mathrm{mb}, 0.4$ at $400 \mathrm{mb}$, and 0.2 at $500 \mathrm{mb}$.

The analysis in Fig. 8 shows centers of ascent of $10 \mathrm{~cm} \mathrm{sec}^{-1}$ ahead of the pre-frontal surge and of 20 $\mathrm{cm} \mathrm{sec}-1$ ahead of the primary cold front with a small region of weak subsidence in the pre-frontal cold core at sounding 14 . The subsidence is confined to the lowest and highest levels at sounding 10 , to low levels near the fronts at sounding 20 , and to the middle troposphere at sounding 23, spreading to low levels by sounding 25 . The correspondence of strong ascent to the moisture field (hatched area in Fig. 2) is excellent, but the narrow (small scale) relatively dry zone at Bradley's sounding 18 is not reflected in the hexagon-scale kinematic vertical velocity field. Notice that the drying and the primary and secondary fronts in the mid-troposphere occur before subsidence appears at these levels.

Basically, the pattern of divergence shows vertically arranged cores of opposite signs. Maximum convergence occurs at $600 \mathrm{mb}$ beneath the cores of maximum ascent and again at $500-400 \mathrm{mb}$ above the region of descent at sounding 24 . The standard large scale model of a linear divergence profile with a maximum located at the surface and a $500-\mathrm{mb}$ level of nondivergence cannot be applied on this $220-\mathrm{km}$ scale.

\section{Low-level jet}

The southerly low-level flow ahead of this storm contained very strong winds just above the surface. Because the strong pressure gradient in this portion of a mature storm is very common, the low-level jet sampled by the Stormy Spring network may be "typical" of intense extratropical cyclones when mountainous terrain does not break up the southerly current. While the 3-hr soundings from Kennedy Airport (JFK) showed no lowlevel wind exceeding $30 \mathrm{~m} \mathrm{sec}^{-1}$, Suffolk County AFB (FOK), $55 \mathrm{n} \mathrm{mi}$ to the east on Long Island, had 40 $\mathrm{m} \mathrm{sec}-1$ winds at as low as $600 \mathrm{~m}$ and had low-level winds exceeding $30 \mathrm{~m} \mathrm{sec}^{-1}$ for $8 \mathrm{hr}$. These southerly winds decreased in speed as the air ascended and moved north through the network.

Fig. 9 contains cross sections approximately parallel 

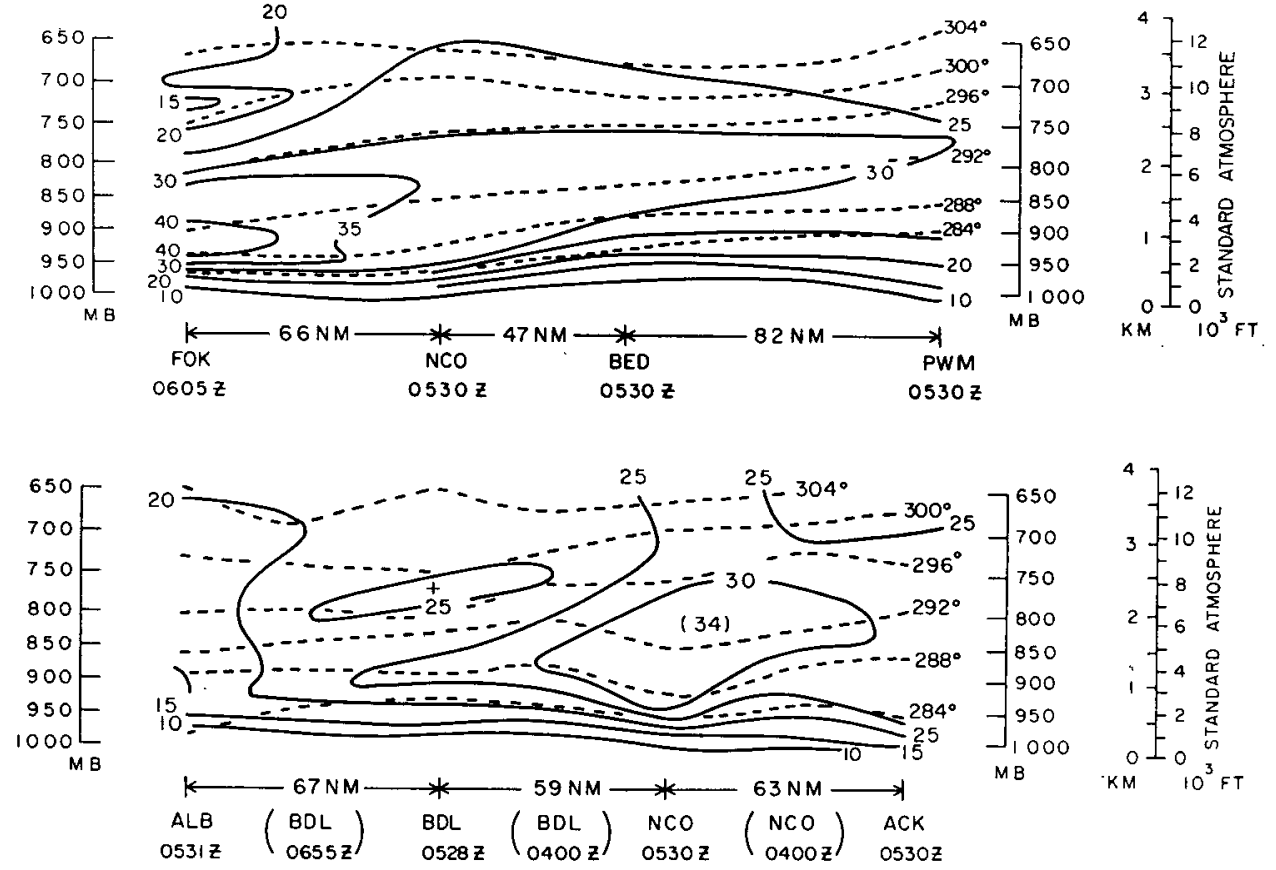

Fig. 9. Cross sections parallel (upper) and normal (lower) to the low-level jet as located in Fig. 10. Solid lines are isotachs in $\mathrm{m} \mathrm{sec}^{-1}$ and dashed lines are isentropes. Off-time soundings were used by converting time to space.

and normal to the jet axis. In the most intense portion of the jet, the wind shear is confined to the lowest levels. Aircraft and rockets would be expected to encounter little shear or turbulence above $1 \mathrm{~km}$, but should aircraft, particularly helicopters, seek refuge from the weather (rain and clouds) by flying low, they would encounter the region of most intense shear. Values of

TABLE 1. Wind shear and Richardson's number (RI) with the low-level jet, 16 April 1965. Heights (HT) are in meters and the shears (DV) are centered vector shears over about $300-\mathrm{m}$ intervals and are expressed in units of $\mathrm{m} \mathrm{sec}^{-1}(500 \mathrm{~m})^{-1}$.

\begin{tabular}{|c|c|c|c|c|c|c|c|c|}
\hline \multicolumn{9}{|c|}{ Suffolk Co. AFB (FOK) } \\
\hline \multicolumn{3}{|c|}{0404 GMT } & \multicolumn{3}{|c|}{0605 GMT } & \multicolumn{3}{|c|}{0745 GMT } \\
\hline $\mathrm{HT}$ & DV & RI & $\mathrm{HT}$ & DV & RI & $\mathrm{HT}$ & DV & RI \\
\hline 163 & 33.6 & 0.17 & 153 & 37.2 & 0.06 & 97 & 35.7 & 0.05 \\
\hline 441 & 22.4 & 0.17 & 427 & 25.1 & 0.19 & 336 & 26.4 & 0.16 \\
\hline 732 & 17.7 & 0.23 & 715 & 18.6 & 0.33 & 615 & 15.3 & 0.46 \\
\hline 1042 & 13.0 & 0.40 & 1018 & 12.8 & 0.22 & 914 & 11.3 & 0.31 \\
\hline \multicolumn{9}{|c|}{ Quonset Pt. NAS (NCO) } \\
\hline \multicolumn{3}{|c|}{0400 GMT } & \multicolumn{3}{|c|}{$0530 \mathrm{GMT}$} & \multicolumn{3}{|c|}{0716 GMT } \\
\hline HT & DV & RI & $\mathrm{HT}$ & DV & RI & HT & DV & $\mathrm{RI}$ \\
\hline 79 & 24.2 & 0.10 & 128 & 28.6 & 0.12 & 155 & 24.0 & 0.18 \\
\hline 343 & 11.5 & 0.65 & 394 & 15.5 & 0.52 & 435 & 16.6 & 0.36 \\
\hline 607 & 7.4 & 1.22 & 673 & 8.7 & 0.94 & 716 & 13.5 & 0.44 \\
\hline 901 & 11.5 & 0.58 & 971 & 10.1 & 0.46 & 1016 & 14.6 & 0.33 \\
\hline \multicolumn{9}{|c|}{ Bradley Field (BDL) } \\
\hline \multicolumn{3}{|c|}{0400 GMT } & \multicolumn{3}{|c|}{0528 GMT } & \multicolumn{3}{|c|}{0655 GMT } \\
\hline $\mathrm{HT}$ & DV & RI & HT & DV & RI & $\mathrm{HT}$ & DV & RI \\
\hline 154 & 16.6 & 0.13 & 161 & 17.9 & 0.11 & 146 & 17.7 & 0.08 \\
\hline 412 & 11.4 & 0.36 & 426 & 12.1 & 0.26 & 403 & 11.1 & 0.38 \\
\hline 695 & 12.1 & 0.22 & 709 & 11.7 & 0.87 & 683 & 12.2 & 0.49 \\
\hline 993 & 14.9 & 0.39 & 1012 & 9.4 & 0.56 & 988 & 8.2 & 1.43 \\
\hline
\end{tabular}

vector wind shear and Richardson's number RI are listed in Table 1 for three sequential soundings at three different sites. Maximum shear and minimum RI occur at the lowest level and have extreme values of 37.2 $\mathrm{m} \mathrm{sec}^{-1}(500 \mathrm{~m})^{-1}$ and 0.05 at FOK which has the most overwater fetch.

The $292 \mathrm{~K}$ potential temperature $(\theta)$ level can be seen in Fig. 9 to coincide closely with the jet core and Fig. 10 shows the isentropic chart for this level. The "horizontal" extent and nature of the low-level jet can be

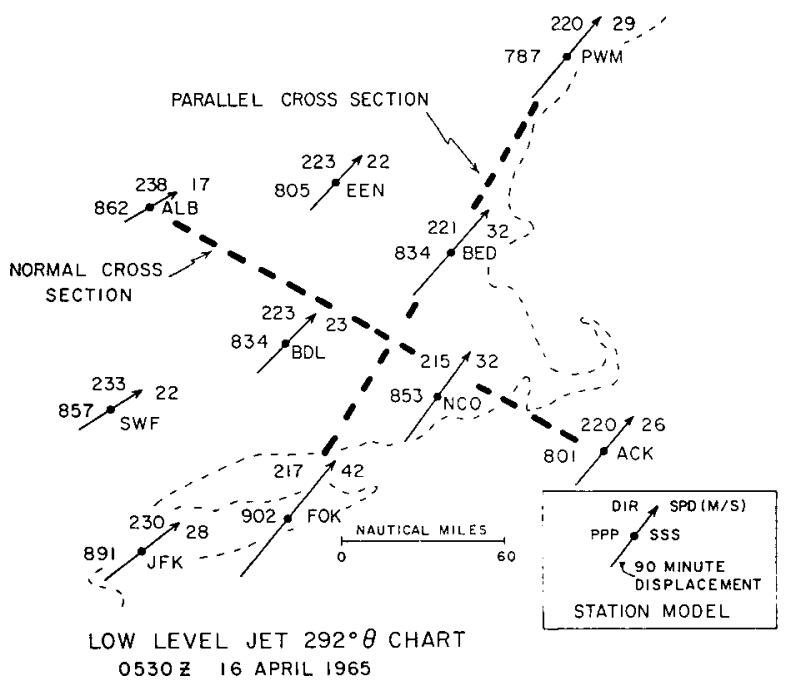

FIG. 10. Plane section for the $292 \mathrm{~K}$ potential temperature level. Winds are plotted with lengths equal to 90 -min displacements. Heavy dashed lines locate the cross sections shown in Fig. 9. 
seen in Fig. 10 along with the location of the cross sections. The cyclonic shear vorticity to the left of the jet core is very large $\left(16 \times 10^{-5} \mathrm{sec}^{-1}\right.$ in the area bounded by FOK, BDL and SWF) and these large low-level vorticities persisted until about 0830 GMT.

The increase in low-level vorticity occurred during the period of mid-tropospheric subsidence and weak ascent shown in Fig. 8 from 0230 to 0530 GMT. The decrease in low-level vorticity occurred during strong ascent between 0830 and 1130 GMT. The vorticity term in the simple quasi-geostrophic $\omega$ equation would account for just such a correlation if one attributes the local vorticity changes to advective changes.

The wind speed and potential temperature profiles for three consecutive sounding times are shown in Fig. 11 for NCO and BDL. The strong shear occurs
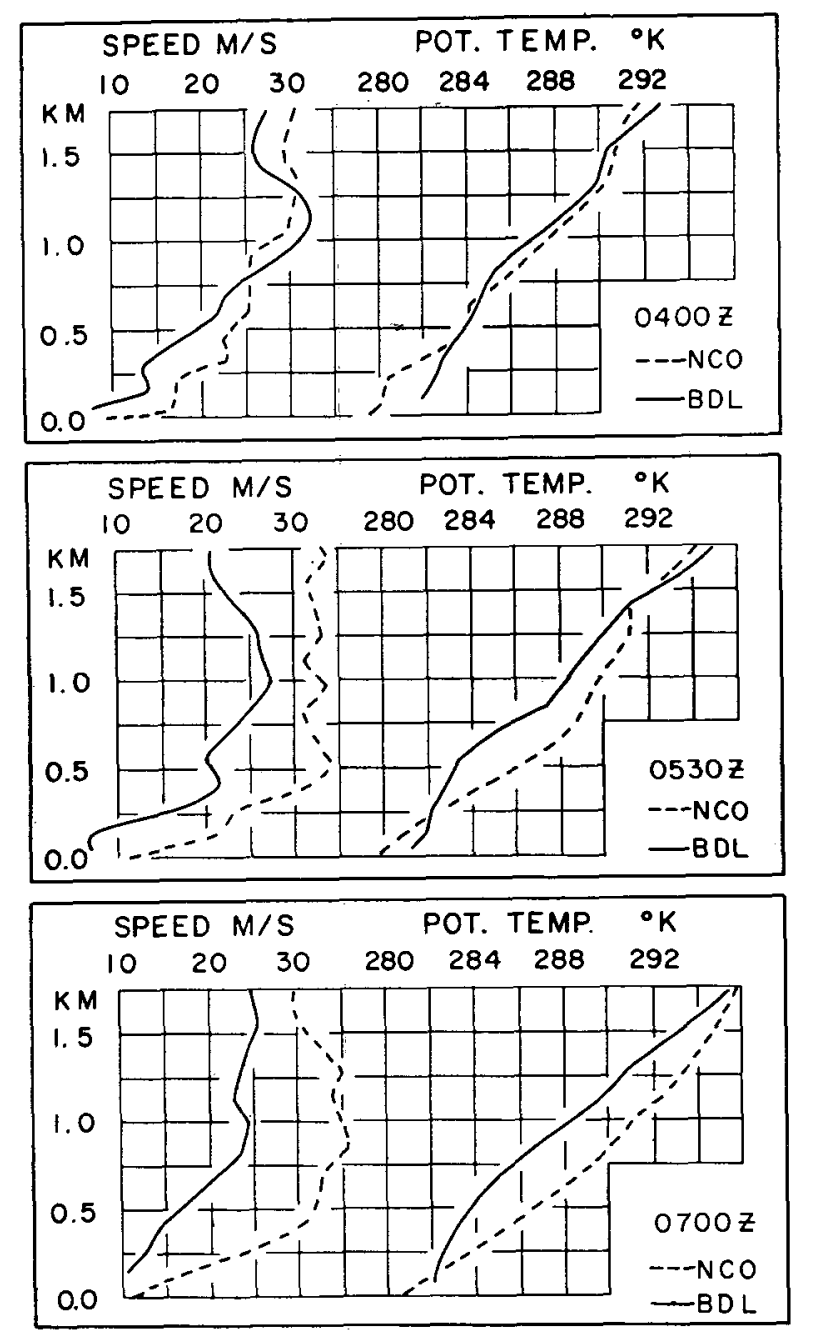

$$
\frac{\partial V_{G}(M / S)}{\partial Z(250 M)} \approx 0.77 \quad[\theta(N C O)-\theta \cdot(B D L)]
$$

FIG. 11. Profiles of wind speed and potential temperature through the low-level jet. The speeds are from essentially 1-min displacements, and the appropriate thermal wind relation normal to the NCO-BDL line is shown by the equation. under stable conditions, but there appears to be no consistent relation between lapse-rate changes and wind shear changes with either height or time.

Since this pair of sites is oriented normal to the wind shear vector in the lower layers, their temperature differences give a thermal wind or geostrophic wind shear which can be compared with the observed wind shear. Obviously, the strong shear is mainly ageostrophic, a fact which is brought out in Fig. 12.

The hodographs in Fig. 12 were prepared using mean winds and geostrophic winds in the area BED, NCO, FOK and BDL. The ageostrophic wind is simply the wind minus the geostrophic wind. Thus, the extreme shears occur in the layer of adjustment to the geostrophic value, that is, in the layer beneath the gradient-wind level which happens to be at $850 \mathrm{mb}$.

A more extensive study of such low-level geostrophic and ageostrophic hodographs (Kreitzberg, 1967) revealed that the ageostrophic hodographs do change in a systematic manner as the storm passes over the network. The geostrophic shears are smaller than but not negligible in comparison with the ageostrophic shears. Furthermore, calculations show that the local acceleration term in the equation of motion is comparable in magnitude to the ageostrophic and the viscous terms and that a steady-state condition is not encountered.

\section{Level of maximum wind and tropopause}

The ridge downstream from the main storm contained a jet stream which, on its anticyclonic side, had a sharply peaked wind maximum in the vertical and a weil-defined tropopause (Fig. 2). These features were relatively well defined and coincident with each other throughout the network for a $6-\mathrm{hr}$ period. The profiles of wind speed and potential temperature for eight

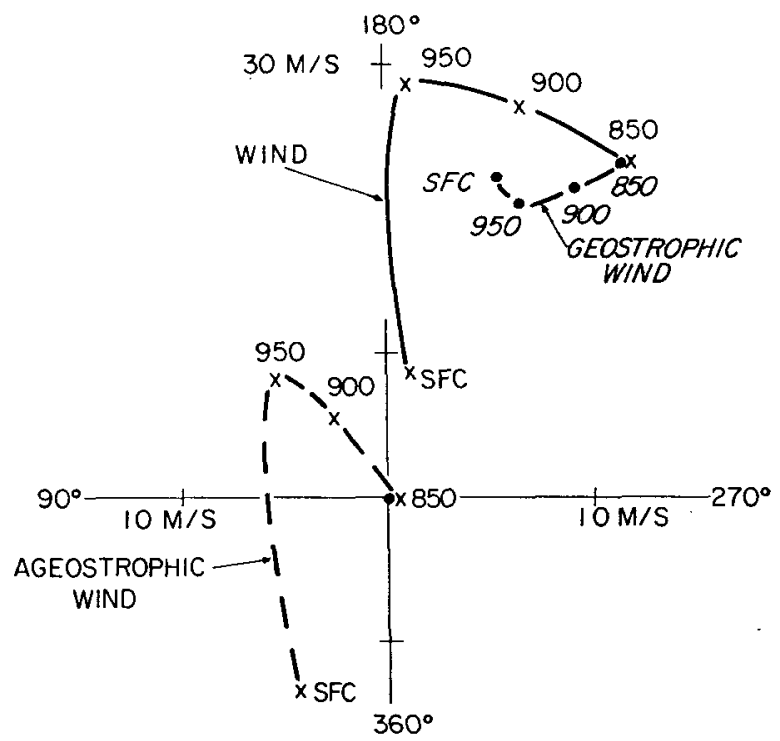

FIG. 12. Hodographs of the wind and the geostrophic and ageostrophic components. Values are plotted for the surface, 950-, 900and $850-\mathrm{mb}$ levels. 

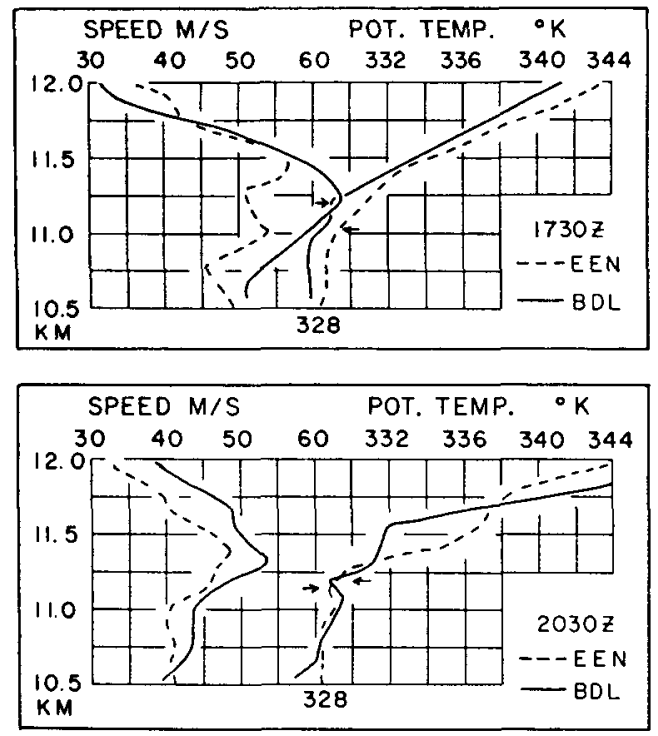

$$
\frac{\partial V_{G}(M / S)}{\partial Z(250 M)} \approx 0.63[\theta(B D L)-\theta(E E N)]
$$
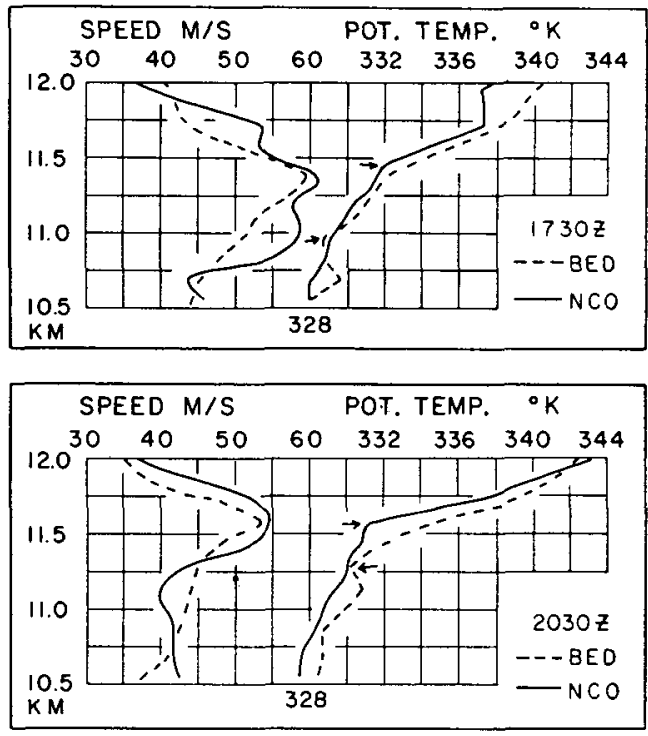

$$
\frac{\partial V_{G}(M / S)}{\partial z(25 O M)} \approx 0.76[\theta(N C O)-\theta(B E D)]
$$

FIG. 13. Profiles of wind speed and potential temperature through the level of maximum wind. The speeds and thermal wind relations are as described in Fig. 11. Arrows mark the bases of stable layers at the tropopause.

soundings through this structure can be seen in Fig. 13. The arrows mark the bases of stable layers corresponding to the tropopause. Actually the tropopause location has some ambiguity because it is well located at a potential temperature of about $329 \mathrm{~K}$ at EEN (both times) and BDL (1730 GMT) and at about $331.5 \mathrm{~K}$ at NCO (both times), while BED (1730 GMT) and BDL (2030 GMT) have indications of both stability-change layers. In spite of such minor discrepancies, the level of maximum wind in all cases lies within $100-300 \mathrm{~m}$ of the tropopause, which is amazingly good considering the speed and shear in this current in the free atmosphere.

The shear is strong above and below the level of maximum wind, but the shear is usually stronger above in the more stable region. Richardson's number is about 0.2 both above and below the speed maximum. Values of vector shear are about +10 to $+15 \mathrm{~m} \mathrm{sec}^{-1}(500 \mathrm{~m})^{-1}$ below and -20 to -30 above, with components of shear normal to the wind being -4 below and +10 above (the wind backs below and veers above the speed maxima).

Since the level of maximum wind is close to the $332 \mathrm{~K}$ surface on all ascents in Fig. 13, the $332 \mathrm{~K}$ plane section is shown in Fig. 14 on two scales. The mesoscale chart shows the Stormy Spring data at 1730 GMT, while the cyclonic scale chart is at the synoptic time $6 \mathrm{hr}$ earlier. The ridge jet at Buffalo (BUF) on the synoptic chart has moved into the Stormy Spring area by 1730 GMT. Fig. 3 shows that the $270^{\circ}$ winds at these levels reached BDL about 2030 GM'T. The BUF sounding showed the same sharp level of maximum wind coincident with the tropopause at $330 \mathrm{~K}$. Thus, this detailed feature retained continuity as it moved with the cyclonic scale pattern.

The inability of geostrophic theory to account for this sharp level of maximum wind is brought out clearly in Fig. 13. These profiles are paired such that the pairs of sites are approximately normal to the wind shear. The geostrophic shears are about $-1 \mathrm{~m} \mathrm{sec}^{-1}(500 \mathrm{~m})^{-1}$ below the speed maxima where the wind shear is +10 to +15 . Above the speed maxima, thermal winds are about -2 while wind shears are -20 to -30 .

Thus, this phenomenon of a sharp jet coincident with the tropopause has good cyclonic scale continuity, good mesoscale organization, and essentially ageostrophic shears with magnitudes comparable to clear air turbulence cases. At 1838 GMT, the U-2 aircraft on a Stormy Spring mission ascended through this $332 \mathrm{~K}$ level $28 \mathrm{nmi}$ north of Bedford and encountered light turbulence. On the descent near Bradley at 2030 GMT, the pilot also reported turbulence below the speed maxima. On the cyclonic scale, a Boeing 707 reported moderate turbulence between Huguenot, N. Y. (near SWF) and Erie, Pa., at $10.7 \mathrm{~km}$ at $1304 \mathrm{GMT}$.

\section{Jet-front shear zone}

Beneath the main jet stream, a narrow zone of extreme wind shear was encountered which coincided roughly with a stable zone and may be similar to the "jet front" (Endlich and McLean, 1957). The directions and speeds at the base and top of this shear zone are plotted on Fig. 3 for ascents 14-19.

Profiles of wind speed and potential temperature for 

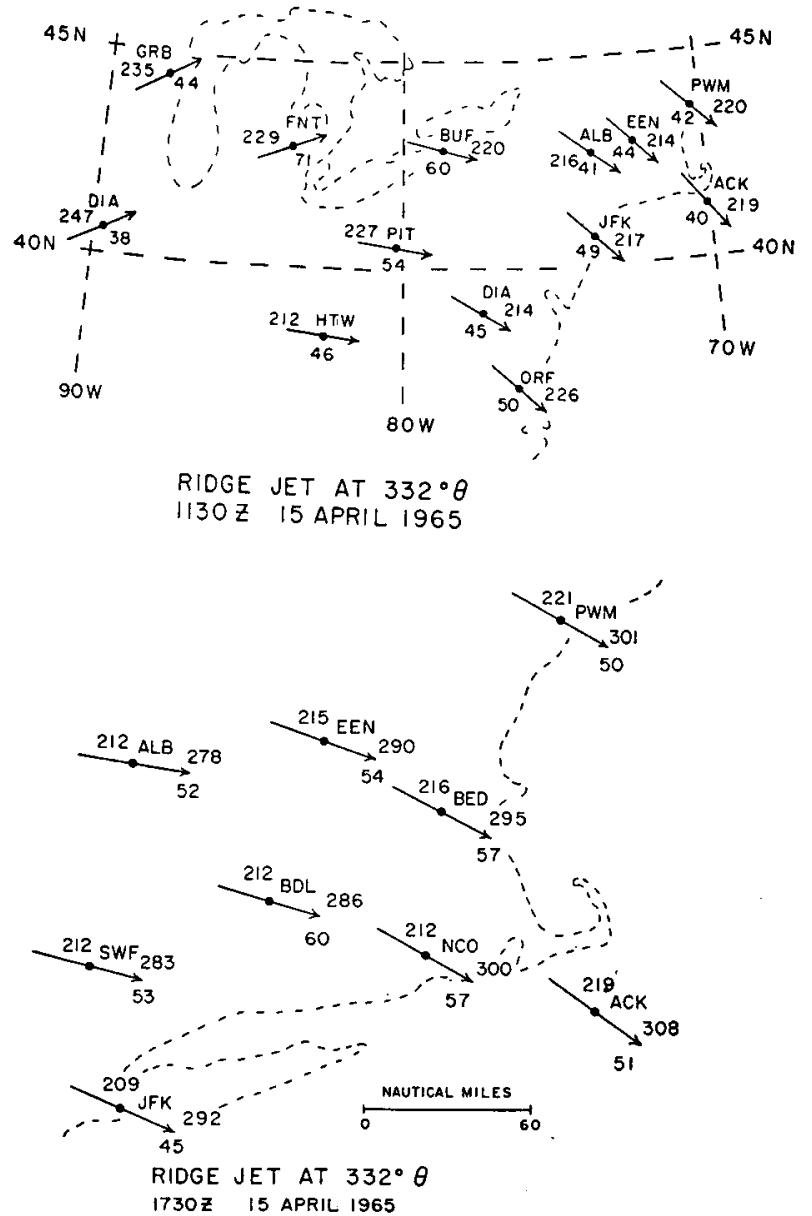

FIG. 14. Ridge jet on the cyclonic scale (upper) and the mesoscale (lower) $332 \mathrm{~K}$ potential temperature charts. The pressures (mb) and"wind speeds $\left(\mathrm{m} \mathrm{sec}^{-1}\right)$ are plotted on the cyclonic scale chart and, in addition, the wind direction is plotted on the mesoscale chart.

four ascents through this feature are shown in Fig. 15. The EEN (0530 GMT) ascent shows a stable lamina from 321 to $325 \mathrm{~K}$ which is "close" to the shear zone from 38 to $63 \mathrm{~m} \mathrm{sec}^{-1}$ in about a $600-\mathrm{m}$ layer. The BDL (0530 GMT) profile shows evidence of the same stable layer but not a comparably well organized shear zone. Furthermore, the BDL (0400) and BED (0530) ascents show that the shear features were encountered before and ahead of the stable lamina, respectively.

Analysis of all soundings from all sites has led to the conclusion that the stable zone had spacial continuity for a number of hours as did the shear zone. However, these two zones were not well correlated. The shear zone was quasi-horizontal while the stable zone sloped steeply upward becoming quasi-horizontal upon merging with or passing through the shear zone.

The wind shear can be compared with the geostrophic wind shear (thermal wind) in Fig. 16. The data on this diagram are means for the $300-250 \mathrm{mb}$ layer which includes the shear zones shown on the profiles in Fig. 15.
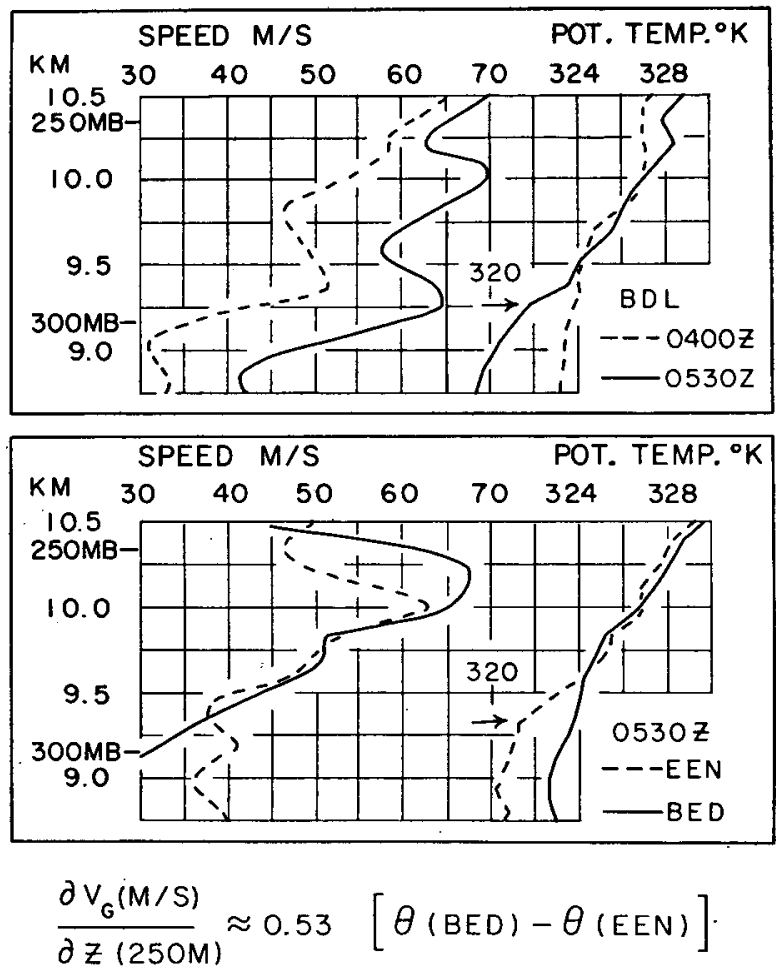

FIG. 15. Profiles of wind speed and potential temperature through the jet-front shear zone. The speeds and thermal wind relations are as described in Fig. 11. Arrows mark bases of stable layers associated with the jet front.

The shear from 300 to $250 \mathrm{mb}$ at each site is used to compute the apparent temperature gradient $\nabla T_{A P P}$ using wind shear in place of geostrophic wind shear in the thermal wind relation. Also the temperature gradient $\nabla T_{C A L}$ can be calculated directly for any triangular array of sites using the layer mean temperatures plotted at the sites in Fig. 16. At the centers of four triangular arrays in this figure, the $\nabla T_{C A L}$ vectors have been plotted along with averages of the $\nabla T_{A P P}$ vectors from the sites in the triangle.

The calculated temperature gradients are "light and variable" compared to the temperature gradients implied from the wind shear. Thus, the shears are mainly ageostrophic, a fact which can be seen in greater detail in Fig. 15 by comparing temperature differences between EEN and BED. The shears are about $15 \mathrm{~m} \mathrm{sec}^{-1}$ $(250 \mathrm{~m})^{-1}$ with geostrophic shears of 0 to 1 .

Numerical values of shear and stability are included in Table 2 to permit quantitative evaluation of spacial continuity of shear and stability features and their correlations. The detailed speed profiles in Figs. 11, 13 and 15 are for winds computed from displacement over about 1-min intervals. The winds in the tables and used in shear calculations are essentially 2 -min mean winds obtained by smoothing the detailed winds with a 1-2-1 weighted running mean. The shears and stabilities in the table are obtained by vertical differencing from 


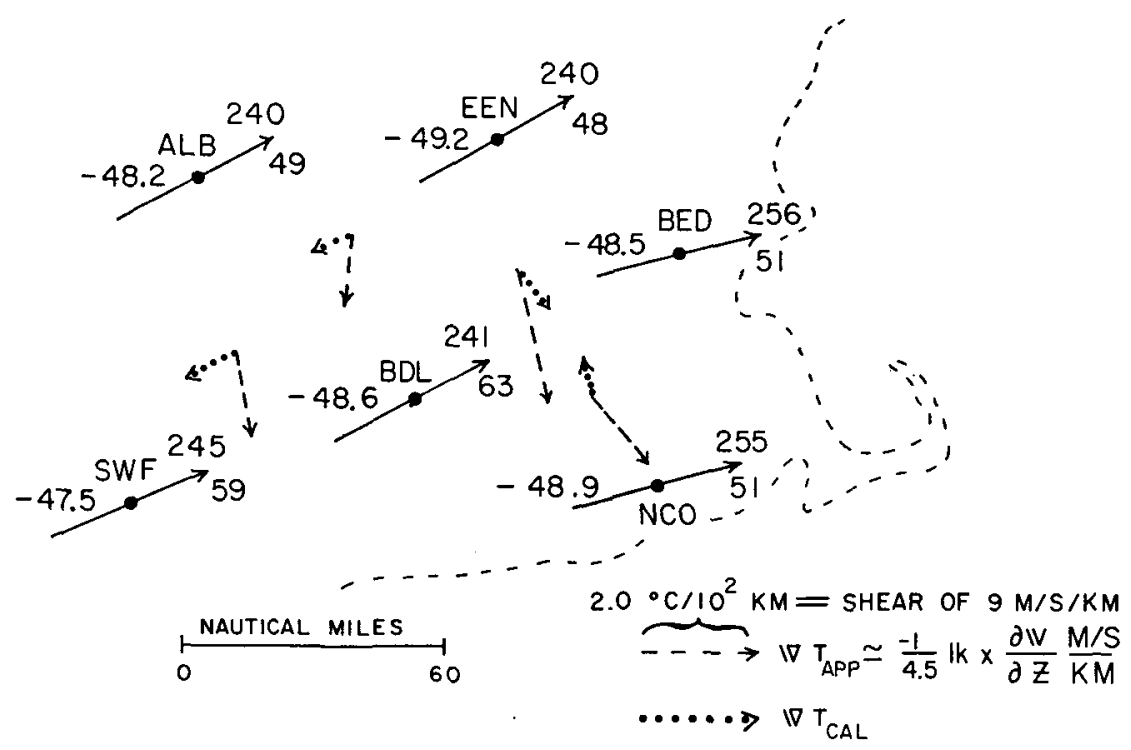

FIG. 16. Comparison of calculated temperature gradients $\nabla T_{C A L}$ with those implied by the wind shear through the jet-front shear zone $\nabla T_{A P P}$ for the $300-250 \mathrm{mb}$ layer at $0530 \mathrm{GMT}$ 16 April 1965 . The $50-\mathrm{mb}$ mean values of temperature $\left({ }^{\circ} \mathrm{C}\right)$ and wind direction and speed $(\mathrm{m} \mathrm{sec}-1)$ are plotted at the rawinsonde sites.

the level above to the level below; thus, they are centered differences over about 300 -m intervals.

The wind direction angular change in Table 2 is $D A / D Z$ with veering winds having positive signs. The shears normal and tangent to the direction at the midpoint of the layer are $D V N / D Z$ and $D V T / D Z$, respectively. The total or vector shear is $D V V / D Z$, the lapse rate $(\partial \theta / \partial z)$ is $D T H / D Z$ and RI is the Richardson's number. The very low RI occur with high shear except at the lowest levels at $\mathrm{NCO}$ and BED where negative lapse rate occurs. The high shears occur in two zones (marked LO and $\mathrm{HI}$ ) at $321-325 \mathrm{~K}$ and at $328 \mathrm{~K}$ or higher. The lower zone is referred to as the jet front in this paper while the higher zone extends upward to the jet core. Both shear zones have RI less than 0.12 except at ALB where the shear zone is relatively weak. These zones with very low RI do apparently have reasonably good spacial continuity.

\section{Summary and conclusions}

While examining the mesoscale structure of one storm, some of the capabilities and limitations of a mesoscale rawinsonde network have come to light. There are a great many mesoscale structures in the atmosphere which have amplitudes that are large with respect to observational errors in the rawinsonde system. It is the nonlinearity of the data in space and time rather than instrumental accuracy which limits the accuracy of calculating wind and temperature gradients. The problem of computing accurate isobaric height gradients at high levels is acute, but thermal winds and ageostrophic wind shears depend on temperature gradients rather than height gradients and are easily obtained for layers on the order of $1 \mathrm{~km}$ in depth.

The principal conclusions regarding mesoscale wind structures within this mature cyclone can be summarized as follows.

1) The main regions of veering and backing with height are only loosely related to either gross or mesoscale frontal structures. Some changes of wind direction do coincide with stable lamina but such relations often have poor continuity in space and time.

2) The main mesoscale regions of veering and backing with time at a site (or along the direction of motion of the cyclonic scale pattern) are associated with five meso-troughs in the streamline pattern. These features are nearly vertical and move with close to the speed of the wind normal to them. The first three troughs were in a barotropic region and there is no apparent divergence pattern associated with them. Negative absolute vorticity on a $110-\mathrm{km}$ scale is observed on both sides of the third meso-trough as well as on the anticyclonic side of the main jet and the jet in the downstream ridge.

3) The shear from a particular hodograph over a 100-mb layer can not be considered a good indicator of temperature gradient on a $220-\mathrm{km}$ scale. Furthermore, layers of intense wind shear do not have comparable values of geostrophic wind shear (or thermal wind).

4) Maximum ascent on the $220 \mathrm{~km}$ scale in this moderately intense cyclone is on the order of $20 \mathrm{~cm}$ $\mathrm{sec}^{-1}$ and weak ascent persists in the middle troposphere during the early period of cold advection, cooling, clearing and drying.

5) Divergence patterns on the $220-\mathrm{km}$ scale have vertically aligned pairs of cells of opposite sign. Rather 
TABLE 2. Wind shear, stability and Richardson's number RI in the jet-front shear zone. Values listed include height HT (m), potential temperature TH $\left({ }^{\circ} \mathrm{K}\right)$, direction DIR $(\mathrm{deg})$, speed SPD $\left(\mathrm{m} \mathrm{sec}^{-1}\right)$ and pressure $P(\mathrm{mb})$. The shear angle $D A / D Z$ and normal, parallel and total shear components $D V N / D Z, D V T / D Z$ and $D V V / D Z$ as well as the stability $D T H / D Z=\partial \theta / \partial z$ are expressed in units of change per $500 \mathrm{~m}$.

\begin{tabular}{|c|c|c|c|c|c|c|c|c|c|c|}
\hline \multicolumn{11}{|c|}{ Albany (ALB) 0531 GMT 16 April 1965} \\
\hline $\mathrm{HT}$ & TH & DIR & SPD & $D A / D Z$ & $D V N / D Z$ & $D V T / D Z$ & $D V V / D Z$ & $D T H / D Z$ & $\mathrm{RI}$ & $P$ \\
\hline $\begin{array}{l}10239 \\
10096\end{array}$ & $\begin{array}{l}329.1 \\
3282\end{array}$ & 242 & 50.1 & 1.7 & 1.5 & -1.6 & 2.2 & 3.4 & 10.25 & 252 \\
\hline $\begin{array}{r}10096 \\
9950\end{array}$ & $\begin{array}{l}328.2 \\
327.6\end{array}$ & $\begin{array}{l}242 \\
242\end{array}$ & 51.1 & & & & & & & 257 \\
\hline 9796 & 326.7 & $\begin{array}{l}242 \\
241\end{array}$ & $\begin{array}{l}48.8 \\
47.5\end{array}$ & 0.8 & 0.6 & 6.0 & 6.1 & 2.4 & 0.99 & 263 \\
\hline 9631 & 325.7 & 240 & 47.0 & 3.6 & 3.0 & 0.4 & 3.0 & 2.1 & 3.56 & $\begin{array}{l}209 \\
276\end{array}$ \\
\hline 9475 & 325.4 & 239 & 47.2 & & & W.T & & & & 283 \\
\hline 9327 & 323.5 & 237 & 49.8 & 3.8 & 3.1 & -4.1 & 5.1 & 5.9 & 3.40 & 289 \\
\hline 9175 & 321.8 & 237 & 49.6 & & & & & & & 296 \\
\hline $\begin{array}{l}9020 \\
8860\end{array}$ & $\begin{array}{l}320.9 \\
3205\end{array}$ & 237 & $\begin{array}{l}46.7 \\
430\end{array}$ & 0.5 & 0.4 & 10.6 & $10.6 \mathrm{LO}$ & 2.1 & 0.29 & 303 \\
\hline 8705 & 320.3 & $\begin{array}{l}230 \\
234\end{array}$ & $\begin{array}{l}4.0 \\
41.2\end{array}$ & 7.7 & 5.7 & 2.7 & 6.3 & 1.3 & 0.49 & $\begin{array}{l}310 \\
317\end{array}$ \\
\hline \multicolumn{11}{|c|}{ Bradley Field (BDL) 0528 GMT 16 April 1965} \\
\hline $\begin{array}{l}10348 \\
10210\end{array}$ & 327.9 & 243 & 65.7 & 1.5 & 1.8 & 5.5 & 5.8 & 0.6 & 0.26 & 249 \\
\hline 10076 & 327.5 & $\begin{array}{l}243 \\
243\end{array}$ & $\begin{array}{l}65.5 \\
66.9\end{array}$ & 1.0 & 1.2 & -3.8 & 40 & 36 & 3,40 & $\begin{array}{l}254 \\
259\end{array}$ \\
\hline 9952 & 326.5 & 242 & 67.5 & & & & 4.0 & 3.0 & 3.40 & 264 \\
\hline 9824 & 326.0 & 242 & 64.0 & 1.1 & 1.2 & 13.2 & 13.3 & 1.9 & 0.16 & 269 \\
\hline 9684 & 325.5 & 242 & 60.4 & & & & & & & 275 \\
\hline 9535 & 324.2 & 241 & 60.1 & 2.7 & 2.9 & -2.7 & 3.9 & 3.2 & 3.18 & 282 \\
\hline 9395 & 323.6 & 240 & 61.9 & & & & & & & 288 \\
\hline 9263 & 321.8 & 239 & 61.6 & 4.8 & 4.9 & 12.0 & 12.9 & 5.1 & 0.47 & 293 \\
\hline 9135 & 321.0 & 238 & 55.7 & & & & LO & & & 299 \\
\hline 8998 & 320.2 & 237 & 47.9 & 2.7 & 2.4 & 21.9 & 22.1 & 2.5 & 0.08 & 305 \\
\hline 8850 & 319.6 & 236 & 43.2 & & & & & & & 312 \\
\hline 8705 & 319.1 & 236 & 41.9 & 1.0 & 0.7 & 1.8 & 2.0 & 0.6 & 2.36 & 319 \\
\hline \multicolumn{11}{|c|}{ Stewart AFB (SWF) 0530 GMT 16 April 1965} \\
\hline 10430 & 330.5 & 247 & 66.6 & 0.6 & 0.6 & -24.4 & 24.4 & 3.0 & 0.08 & 246 \\
\hline $\begin{array}{l}10290 \\
10154\end{array}$ & $\begin{array}{l}329.3 \\
3200\end{array}$ & 247 & $\begin{array}{l}69.1 \\
62.8\end{array}$ & 1.0 & & & $\mathrm{HI}$ & & & 251 \\
\hline 10028 & $\begin{array}{l}329.0 \\
328.6\end{array}$ & $\begin{array}{l}247 \\
246\end{array}$ & $\begin{array}{l}62.8 \\
57.0\end{array}$ & 1.0 & 1.0 & 23.2 & 23.2 & 1.4 & 0.04 & 257 \\
\hline 9901 & 328.3 & 246 & 57.1 & 3.0 & 3.0 & -1.0 & 3.2 & 2.6 & 3.88 & 267 \\
\hline 9765 & 327.2 & 245 & 57.5 & & & & & & & 272 \\
\hline 9618 & 326.4 & 244 & 57.6 & 2.8 & 2.9 & -5.0 & 5.8 & 2.7 & 1.23 & 279 \\
\hline 9476 & 325.6 & 243 & 60.4 & & & & & & & 285 \\
\hline 9342 & 324.9 & 243 & 61.0 & 1.3 & 1.3 & 9.7 & 9.8 & 3.8 & 0.60 & 290 \\
\hline 9214 & 323.6 & 243 & 55.3 & & & & LO & & & 296 \\
\hline 9079 & 322.5 & 243 & 47.4 & 2.0 & 1.5 & 21.5 & 21.5 & 3.2 & 0.11 & 302 \\
\hline 8928 & 321.8 & 241 & 43.0 & & & & & & & 309 \\
\hline 8787 & 320.5 & 239 & 45.4 & 8.8 & 6.8 & -5.0 & 8.4 & 2.7 & 0.58 & 315 \\
\hline \multicolumn{11}{|c|}{ Keene (EEN) 0549 GMT 16 April 1965} \\
\hline 10391 & 328.3 & 245 & 48.5 & 4.2 & 3.7 & -8.1 & 8.9 & 3.4 & 0.64 & 246 \\
\hline 10256 & 327.8 & 243 & 51.1 & & & & & & & 251 \\
\hline 10115 & 326.9 & 241 & 56.7 & 5.5 & 5.1 & -13.2 & 14.2 & 1.5 & 0.11 & 256 \\
\hline $\begin{array}{l}9989 \\
9865\end{array}$ & $\begin{array}{l}327.0 \\
325.5\end{array}$ & $\begin{array}{l}240 \\
240\end{array}$ & $\begin{array}{l}58.2 \\
55.4\end{array}$ & 0.8 & 0.8 & 16.4 & 16.4 & 3.4 & & 261 \\
\hline $\begin{array}{l}9865 \\
9741\end{array}$ & $\begin{array}{l}325.5 \\
325.3\end{array}$ & $\begin{array}{l}240 \\
240\end{array}$ & $\begin{array}{l}55.4 \\
50.1\end{array}$ & & & & ${ }^{10} \mathrm{LO}$ & 3.4 & 0.19 & 266 \\
\hline 9610 & $\begin{array}{l}325.3 \\
324.2\end{array}$ & 239 & 45.4 & 1.2 & 1.0 & 15.7 & 15.7 & 4.7 & & 271 \\
\hline 9470 & 322.7 & 239 & 41.5 & & & & & & 0.29 & 277 \\
\hline 9336 & 321.4 & 239 & 39.5 & 1.5 & 1.0 & 4.7 & 4.8 & 3.2 & 2.08 & $\begin{array}{l}283 \\
280\end{array}$ \\
\hline 9209 & 321.1 & 238 & 39.1 & & & & & & 2.00 & 294 \\
\hline 9079 & 320.7 & 239 & 38.5 & -2.9 & -2.0 & 1.9 & 2.7 & 1.6 & 3.46 & 300 \\
\hline 8939 & 320.2 & 240 & 38.1 & & & & & & & 306 \\
\hline 8796 & 320.7 & 238 & 38.4 & 7.1 & 4.7 & 0.3 & 4.7 & 0.4 & 0.26 & 313 \\
\hline
\end{tabular}

than a linear profile through a mid-tropospheric level of nondivergence, one finds centers of maximum convergence at $600 \mathrm{mb}$ during periods of maximum ascent and at $450 \mathrm{mb}$ above the cold descending air.

6) The low-level jet in the southerly flow ahead of the storm contained extreme wind shear and low Richardson number in the layer of adjustment to geo- strophic balance. Since strong surface pressure gradients frequently are found ahead of mature cyclones, this phenomena with the associated hazards to aircraft (particularly helicopters) may be common where terrain features do not disrupt the southerly current.

7) A sharp level of maximum wind was observed to coincide well with the tropopause on the anticyclonic 
TABLE 2 (continued).

\begin{tabular}{|c|c|c|c|c|c|c|c|c|c|c|}
\hline \multicolumn{11}{|c|}{ Bedford (BED) 0530 GMT 16 April 1965} \\
\hline $\mathrm{HT}$ & TH & DIR & SPD & $D A / D Z$ & $D V N / D Z$ & $D V T / D Z$ & $D V V / D Z$ & $D T H / D Z$ & RI & $P$ \\
\hline 10255 & 328.3 & 254 & 63.9 & 8.2 & 8.5 & -18.2 & 20.1 & 2.4 & 0.09 & 253 \\
\hline 10111 & 327.5 & 253 & 66.1 & & & & HI & & & 259 \\
\hline 9966 & 326.5 & 254 & 60.7 & -5.0 & -5.1 & 19.6 & 20.2 & 4.4 & 0.16 & 265 \\
\hline 9834 & 325.1 & 256 & 55.3 & & & & & & & 270 \\
\hline 9706 & 324.8 & 258 & 50.1 & -5.0 & -4.7 & 16.3 & 16.9 & 2.0 & 0.11 & 276 \\
\hline 9567 & 324.0 & 258 & 46.6 & & & & & & & 282 \\
\hline 9418 & 323.8 & 258 & 41.3 & 0.4 & 0.4 & 18.9 & $18.9 \mathrm{LO}$ & 0.9 & 0.04 & 288 \\
\hline 9280 & 323.5 & 258 & 35.7 & & & & & & & 294 \\
\hline 9145 & 323.0 & 259 & 31.0 & -3.9 & -2.0 & 16.8 & 16.9 & 1.6 & 0.09 & 300 \\
\hline 9008 & 322.6 & 260 & 26.6 & & & & & & & 306 \\
\hline 8867 & 322.6 & 261 & 23.4 & -3.7 & -1.5 & 10.2 & 10.3 & -0.4 & -0.06 & 313 \\
\hline \multicolumn{11}{|c|}{ Quonset Pt. (NCO) 0530 GMT 16 April 1965} \\
\hline 10423 & 327.7 & 258 & 58.1 & 17.4 & 17.4 & 9.4 & $19.8 \mathrm{HI}$ & 0.8 & 0.03 & 247 \\
\hline 10300 & 327.3 & 255 & 54.5 & & & & & & & 252 \\
\hline 10170 & 326.5 & 254 & 53.4 & -2.6 & -2.6 & -3.2 & 4.1 & 3.2 & 2.80 & 2.57 \\
\hline 10029 & 325.6 & 256 & 56.3 & & & & & & & 263 \\
\hline 9897 & 325.3 & 256 & 56.7 & 1.3 & 1.3 & 2.3 & 2.6 & 1.5 & 3.32 & 268 \\
\hline 9776 & 324.8 & 255 & 55.2 & & & & & & & 273 \\
\hline 9653 & 324.8 & 255 & 52.4 & 2.2 & 1.9 & 11.0 & 11.2 & 1.2 & 0.15 & 278 \\
\hline 9521 & 324.2 & 254 & 49.5 & & & & & & & 284 \\
\hline 9380 & 323.1 & 254 & 45.5 & -1.7 & -1.1 & 15.4 & 15.5 & 3.2 & 0.20 & 290 \\
\hline 9240 & 322.4 & 255 & 40.9 & & & & & & & 296 \\
\hline 9106 & 322.1 & 258 & 35.3 & -10.9 & -6.6 & 20.6 & $21.6 \mathrm{LO}$ & 1.4 & 0.05 & 302 \\
\hline 8974 & 321.6 & 261 & 30.0 & & & & & & & 308 \\
\hline 8836 & 321.7 & 263 & 27.3 & -0.3 & -0.2 & 4.2 & 4.2 & -0.4 & -0.32 & 314 \\
\hline
\end{tabular}

side of the ridge jet. The shears were strong and essentially ageostrophic and the Richardson numbers were low both above and below the speed maxima. The structure had cyclonic scale continuity, excellent mesoscale organization and clear air turbulence was reported both above and below the speed maxima.

8) A zone of intense ageostrophic wind shear was located beneath the main jet and may correspond to the jet front. Both the shear zone and a weak stable layer had continuity in space and time. The shear zone was quasi-horizontal beginning above the stable layer which sloped upward steeply to merge with or pass through the shear zone.

It is important that the mesoscale structures within this storm be compared with structures in other storms sampled by a mesoscale rawinsonde network. It is doubtful that the basic nature of the variability will differ in other storms, but different types of specific structures and repetition of some of the structures in the first storm can be anticipated. In particular, the inference of mesoscale temperature gradients from vertical wind shear and vice versa appear to be futile.

\section{REFERENCES}

Dvoskin, N., and N. Sissenwine, 1958: Evaluation of AN/GMD-2 wind shear data for development of missile design criteria. Air Force Surveys in Geophysics, No. 99, $72 \mathrm{pp}$.

Endlich, R. M., and G. S. McLean, 1957: The structure of the jet stream core. J. Meteor, 14, 543-552.

Ferguson, H. L., 1967: Mathematical and synoptic aspects of small-scale wave disturbance over the lower Great Lakes area. J. A ppl. Meteor., 6, 523-529.

Kreitzberg, C. W., 1964: The structure of occlusions as determined from serial ascents and vertically-directed radar. Air Force Cambridge Research Laboratories, AFCRL-64-26, $121 \mathrm{pp}$.

_-_, 1967: An empirical study of low-level sounding prediction. Proc. Technical Exchange Conf., 4-7 April 1967, Monterey, Calif.; Air Weather Service, AWS Tech. Rept. 196, 262-275.

-_, and W. E. Brockman, 1966: Computer processing of mesoscale rawinsonde data from Project Stormy Spring. Air Force Cambridge Research Laboratories, AFCRL-66-97, Spec. Rept. No. $41,35 \mathrm{pp}$. Copies may be obtained by writing AFCRL (CRMXRA), L. G. Hanscom Field, Bedford, Mass. 01730.

Omoto, Y., 1965: On pre-frontal precipitation zones in the United States. $J$. Meteor. Soc. Japan, 43, 310-330.

Palmén, E., 1951: The aerology of extratropical disturbances. Compendium of Meteorology, Boston, Amer. Meteor. Soc., 599-620. 